\title{
Conditioning and Coordination a Necessity in Appropriation of Learning Program Artistic Gymnastics with Students
}

Natasha Dako, Valbona Puma, Adriatik Meta, Edison Ikonomi*

Department of Sport, Faculty of Movement Sciences, Sports University Tirana, Albania

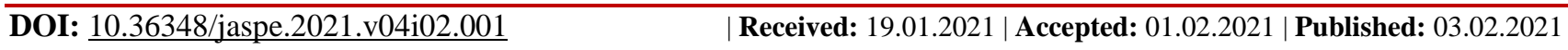

*Corresponding author: Edison Ikonomi

\section{Abstract}

The purpose of this study is to recognize, evaluate, compare and develop the level of conditioning-coordinating preparation of students, in the context of realizing the learning process of program elements in practical lessons. This study was attended by 27 students. Participants were selected randomly (of 10 groups having the 2nd Bachelor course two were separated) and were included in this study at their desire. The student group taken in this study would be trained for 8 weeks, according to a defined physical fitness "supplement" program during this period, with the twice-weekly focus on developing plyometric jump and strength exercises for the major muscle groups., as well as other speed-force coordinate exercises with varying tempo and direction, accompanied by flexion, muscle extension and articulation mobility exercises (stretching). All students included in this study were measured before and after the 8-week training period on the tests: vertical jump, long jump, 20m running, 5x10m running, flexibility, and anthropometric parameters related to these tests. At the end of the training period, the students included in this study had a significant improvement ( $\mathrm{p}<0.05)$, in the vertical jump with the help of the arms with the hands at the waist by $(3.6 \pm 0.05 \mathrm{~cm}$ or $7.4 \%)$ and in the vertical jump with the help of the arms $(4.8 \pm 0.07 \mathrm{~cm}$ or $8.89 \%)$, in the long jump $(9.3 \pm 1.66 \mathrm{~cm}$ or $3.72 \%)$, in $20 \mathrm{~m}$ running $(-0.32 \pm 0.15 \mathrm{sec}$ or $9.6 \%)$, in $5 \times 10 \mathrm{~m}$ running with a change of direction $(-0.28 \pm 0.35 \mathrm{sec}$ or $2.13 \%)$, in flexion of front trunk $(2.22 \pm 2.39 \mathrm{~cm}$ or $18.7 \%)$ as well as back-to-back rotation of the shoulder $(6.63 \pm 3.39 \mathrm{~cm}$ or $7.75 \%)$. These tests were associated with anthropometric parameters such as, age (22.7 years), weight (75.2 $\pm 7.5 \mathrm{~kg})$, height $(1.82 \pm$ $0.07 \mathrm{~cm})$, BMI $(22.4 \pm 1.39)$, fitness index (Esslinger) at first assisted measurement of the arms with a second measurement difference of $1.33 \pm 0.78$ or $1.29 \%$ and without the help of arms with a second measurement difference of $(1.38 \pm 1.02$ or $1.56 \%)$, which had less significant improvements. The results of this study showed that the effects of the plyometric and strength-velocity training methods, coupled with the methods of developing passive-active flexibility, increased with significant indicators especially on the conditioning-coordination performance skills of the students taken in this study.

Keywords: Artistic Gymnastics, Plyometric Strength, Training Method, Physical Fitness Program, High Jump, Long Jump, Development of Passive-Active Flexibility.

Copyright () 2021 The Author(s): This is an open-access article distributed under the terms of the Creative Commons Attribution 4.0 International License (CC BY-NC 4.0) which permits unrestricted use, distribution, and reproduction in any medium for non-commercial use provided the original author and source are credited.

\section{INTRODUCTION}

Plyometric training and other strength development methods have already been acknowledged as the most comprehensive motor skills enhancers in sport, especially in terms of jumping [1] and at the same time a significant component of most skill development programs of physical conditioning. The method of plyometric training of strength-velocity development (or often referred to as group

Stretching and contraction muscle-training exercises) is often used during training programs in various sports and in physical education practical training as an effective method of improving motor performance [2].

The exercise of force as a whole is also an important part of any training program or physical activity in the beginning, with a background associated with benefits that improve conditional performance (motors) and obviously reduce in any case the injuries to the practitioners [3].

Although our focus in this study is to use the exercises of the plyometric method of force, they are certainly not excluded, rather, they are combined with 
the training of total force, for the main body-muscle groups, with the thought and conviction that conditioning performance (motors) can be increased at a significantly greater speed than any other performance program individually [4-6].

The training of the pliometric method firstly affects the neuromuscular system, for the demands of strength training from increased activation of the neural pathways and to a greater degree the readiness of the neuromuscular system [7].

The use of not only pliometric exercises but overall strength exercises included together in training is almost an adequate strategy of training process organization, which has high positive effects on training practice and especially on its rational time management. Also, the increasing demands and popularity that strength conditioning programs have gained among practitioners have undoubtedly increased in addition to their potential health benefits [8] and these are effective methods for enhancing athlete performance in general and in our case students in particular.

The hypothesis of this study is that in addition to other methods of force development coordinated with the plyometric method of education and force development and coupled with methods of developing passive-active and self-conscious flexibility, would undoubtedly result in greater improvement signifiers in conditioning performance skills (motors).

\section{METHODOLOGY}

Two groups of students (out of ten in total) were participants for this study. Students would be trained according to a defined physical fitness "supplement" program for 8 weeks during the training period, with the twice-weekly focus mainly on plyometric exercises for jumping as well as speedstrength running segments changing tempo and direction, gymnastics games and relays, coupled with stretching complexes, to improve this ability as a need for better student performance in group subjects of gymnastics. Changes in all indicators (variables) were measured before and after 8 weeks of program applied training-teaching.

Subjects: Participating students are two Bachelor groups of FSHL in the subject of artistic gymnastics. They were randomly selected from ten parallel groups. Testing of physical abilities was accompanied by anthropometric parameters such as age (22.7 years), weight $(75.2 \pm 7.5 \mathrm{~kg})$, height $(1.82 \pm$ $0.07 \mathrm{~cm})$, BMI $(22.4 \pm 1.39)$. The students participating groups take in this study have an experience in different physical activities, relatively significant, but often trained with training programs in various types of sports or general activities of physical education in schools and not focus to increase the indicators of lower parameters of motor skills such as jump, speed, flexibility, etc. Students participating in these two groups were informed about the nature of this study project and their approval was obtained before the study began. Undoubtedly, the lecturers of artistic gymnastics were also informed about the experimental procedures, the possible dangers of neglecting the requirements of the exercises and the potential benefits of this project. All training sessions were conducted in the UST Gymnastics and Fitness Room.

Procedures: 5 tests were selected for evaluating physical fitness performance. Tests are often used to evaluate the performance of practicing students. Test procedures: vertical jump, long jump, running 20 $\mathrm{m}$ sprint, running $5 \times 10 \mathrm{~m}$ from the high start and stretching as a test of flexibility can be found at [9]. The "supplement" training program used in this study was designed by the authors of this research study and is based on the following publications $[2,10]$.

Both groups of students were trained twice a week, alternating between days, for 8 consecutive weeks (from 19.08.2019 to 19.10.2019). Group lecturers were introduced (through demonstrations) to the technical, rational requirements of each exercise during the study period. The training lessons were supervised in their entirety, led by group lecturers to frequently adjust the nature of the intensity of the teaching-training intensity, in keeping with the task of maintaining the teaching load correctly and without exaggeration. The training sessions lasted 120 minutes, and for the two groups in this study, the "supplement" program of plyometric exercises and strength (conditioning) for 40-45 minutes was developed within the teaching program. The students participating in the training curriculum developed a warm-up period of 10 to 12 minutes, consisting of a moderate intensity, with a range of dynamic exercises different from one another. Recent observations suggest that this may be more effective (ie, warming up) with the warming protocol for boosting, intensifying power performance (ie, the force-to-speed ratio) [9].

After the warm-up period with the two groups in this study, the methodological training of the gymnastic elements provided for the 50-55 minutes continued with the plyometric and strength exercises for 40-45 minutes.

Each training session ended with approximately 5-10 minutes of cooling exercises (mainly flexibility exercises.) While performing this program designed and planned by the lecturers of this experimental study, it was not allowed to change or apply any other program offered by other subjects.

Warm-up protocol: consists of 10-12 minutes with a moderate intensity of jogging, followed by not a moderate intensity but slightly higher dynamic exercise. They include "skip" jogging, knee jogging, heel 
touching, "karaoke" or foot jogging, tempo and running jogging, figure jogging, etc. Detailed descriptions of stretching exercises can be found in the various physical fitness or fitness training associations in general [11]. Training sessions with elements of artistic gymnastics alone, for physical training in different types of training gymnastic in general, should be careful during training sessions, as these types of exercises often add to the monotony and above all chronic stress in the skeletalmuscular system [12].
Plyometric training: the plyometric training program consists of these levels. Student participants perform 10 plyometric exercises during the first and second week ( 1 set of 10 repetitions) and 12 plyometric exercises during the third to sixth weeks. Third and fourth week (1 set of 8 repetitions), and week 5-6 (1 set of 6 repetitions). The exercises were according to the protocols described earlier [2].

Table-1: Summary of teaching-training program plyometric

\begin{tabular}{|c|c|c|}
\hline $\begin{array}{l}\text { Week of } 1-2 \\
1 \text { set / } 8 \text { repetitions }\end{array}$ & $\begin{array}{l}\text { Week of 3-4 } \\
1 \text { set / } 7 \text { repetitions }\end{array}$ & $\begin{array}{l}\text { Week of 5-6 } \\
1 \text { set / } 6 \text { repetitions }\end{array}$ \\
\hline $\begin{array}{l}\text { 1-Quick Skip } \\
20 \text { m long segments }\end{array}$ & $\begin{array}{l}1-\text { Jump up with } \\
\text { heels touching the buttocks }\end{array}$ & $\begin{array}{l}1 \text { - Jumping gallop } \\
\text { with great step forward }\end{array}$ \\
\hline 2 - "Pogo" jump up & 2 - "Pogo" jump up & $\begin{array}{l}2 \text { - Jumping alternately } \\
\text { on one foot over the pod }\end{array}$ \\
\hline 3 - "Rocket jump" up & 3 - Jump up with legs open & 3 - Quick jump. \\
\hline $\begin{array}{l}4-\text { Jump on } \\
\text { the medical ball front-to-back }\end{array}$ & $\begin{array}{l}4 \text { - Jumping "scissors" } \\
\text { front-to-back }\end{array}$ & $\begin{array}{l}4 \text { - Depth jump } \\
\text { top to bottom }\end{array}$ \\
\hline $\begin{array}{l}5 \text { - Jumping to return } \\
360 \text { grade over medical ball }\end{array}$ & $\begin{array}{l}5 \text { - Jumping } \\
\text { with alternating feet }\end{array}$ & $\begin{array}{l}5 \text { - Jump pods in the amount of } \\
\text { repetitions }\end{array}$ \\
\hline $\begin{array}{l}6 \text { - Pass the ball filled with the } \\
\text { jump to the consecutive partner }\end{array}$ & $\begin{array}{l}6 \text { - Jumps } \\
\text { to the return } 360 \text { grade }\end{array}$ & $\begin{array}{l}6-\text { MB throw it } \\
\text { from the bottom-up-back }\end{array}$ \\
\hline $\begin{array}{l}7 \text { - Quick jump } \\
\text { with two consecutive legs }\end{array}$ & 7 - MB up-front to run to catch & $\begin{array}{l}7-\text { Jump and throw } \\
\text { MB overhead waiting }\end{array}$ \\
\hline $\begin{array}{l}8 \text { - Fast progressive jump } \\
\text { with both feet }\end{array}$ & $\begin{array}{l}8 \text { - Climbing leg } \\
\text { stand up and sprinting } 15-20 \mathrm{~m}\end{array}$ & $\begin{array}{l}8 \text { - Jumps and throws MB with } \\
\text { hands from down -up }\end{array}$ \\
\hline 9 - Lateral jump left and right & $\begin{array}{l}9 \text { - Jumping with one } \\
\text { foot alternating with the other }\end{array}$ & 9 - Side jump succession \\
\hline \multirow[t]{3}{*}{$\begin{array}{l}10 \text { - Side jump } \\
15 \mathrm{~m} \text { sprint left and right }\end{array}$} & $\begin{array}{l}10 \text { - Jumping with one foot } \\
\text { in the form of "zigzag" }\end{array}$ & 10 - Pod skip \\
\hline & 11 - Jump with one leg diagonal & 11 -Pod bound \\
\hline & 12 - Jump with one leg in side & $\begin{array}{l}12 \text { - Progressive depth } \\
\text { jump (MR) up and down }\end{array}$ \\
\hline
\end{tabular}

$\mathrm{MB}=$ top medicine; $\mathrm{MR}=$ Multiple Response

\section{STATISTICAL ANALYSIS}

A descriptive analysis (mean + SD) was calculated for all variables. The independent sample ttest was taken to derive the differences between measurements for all baseline variables. Non-variance analysis (ANOVA) was used to determine whether differences existed between measurements in the changes for each variable from the post-test baseline. Where significant and interacting effects were observed after pairing the t-test with a correction (adjustment, decorating) for multiple scores, they were also used to identify specific differences. All data are forwarded to SPSS, version 22.0 (SPSS, Inc. Chicago, IL USA). Significant level was set at $\mathrm{p}<0.05$.

\section{RESULTS}

Table 2 below provides the data on the motor performance before the beginning of the teachingtraining process and at the end with the students taken in this study. Students participating in this study conducted almost $100 \%$ educational training sessions, with the consent of their desire, without causing any damage to them during this training process. Overall, the data obtained after the training program results in positive variables, with an increase in initial values, though not significant in some cases. Let's take each of them individually and discuss them. 
Natasha Dako et al., J Adv Sport Phys Edu, Feb, 2021; 4(2): 10-14

Table-2: Conditioning performance results before and after the experimental period

\begin{tabular}{|l|l|l|l|l|}
\hline No. & \multicolumn{3}{|l|}{ Force-Speed (Power) } & Speed \\
\hline Meas. & $\begin{array}{l}\text { Vertical jump (m) } \\
\text { (Without arms help - hands on waist) }\end{array}$ & $\begin{array}{l}\text { Vertical jump (m) } \\
\text { (With the help of arms) }\end{array}$ & Long jump (cm) & $\begin{array}{l}\text { Running 20 m. } \\
(\mathrm{sec})\end{array}$ \\
\hline 1 st meas. & $0.486 \pm 0.08$ & $0.5398 \pm 0.07$ & $249.53 \pm 1.11$ & $3.33 \pm 0.2$ \\
\hline 2st meas. & $0.522 \pm 0.07$ & $0.5886 \pm 0.05$ & $258.83 \pm 2.21$ & $3.01 \pm 0.1$ \\
\hline Difference & $0.036-7.4 \% *$ & $0.048-8.89 \% *$ & $9.3-3.72 \% *$ & $-0.32-9.6 \% *$ \\
\hline
\end{tabular}

\begin{tabular}{|l|l|l|l|}
\hline No. & Agility & Suppleness \\
\hline Meas. & Running 5x10 m. touch $(\mathrm{Sec})$ & $\begin{array}{l}\text { Flexion trunk before } \\
\text { from sit } \\
(\mathrm{cm})\end{array}$ & $\begin{array}{l}\text { Shoulder rotation with rope, bottom-front- } \\
\text { top-back and vice versa (cm.) }\end{array}$ \\
\hline 1st meas. & $13.39 \pm 0.4$ & $11.86 \pm 1.91$ & $85.46 \pm 4.1$ \\
\hline 2st meas. & $13.11 \pm 0.3$ & $14.08 \pm 2.87$ & $78.83 \pm 3.8$ \\
\hline Difference & $-0.28-2.13 \% *$ & $2.22-18.7 \% *$ & $6.63-7.75 \% *$ \\
\hline
\end{tabular}

Note: * Significant improvements compared to measurement experimental process

\section{DISCUSSION}

Initially in terms of morphological data they have almost no differences from the first measurement to the second, (therefore we have not presented in the table) except for the Esslinger Fitness Index (EFI) with or without the help of arms, which have slight improvements respectively from $1.29 \%$ with the help of arms and $1.56 \%$ without the help of arms. Thus, other morphological indicators for such a short period of time may not have appreciable growth differences. The hypothesis that a combined plyometric training program with other strengths and abilities results in relatively significant improvements in motor performance skills (motors). The students in this study made a significant improvement in strength in the lower and upper body parts, which were seen as an essential requirement of gymnastics performance [1].

The vertical jump without the aid of the arms in the first measurement compared to the second results in a significant average increase in the absolute gain of $3.6 \mathrm{~cm}$, which results in $7.4 \%$. In vertical jump with the help of arms results in an increase of $4.88 \mathrm{~cm}$, which is expressed in percentage to $8.89 \%$ ? So we have a significant increase in these indicators, where the results are an affirmation of previous achievements demonstrated by [4].

We can also say that there is an increased improvement in the long jump distance of students by $9.3 \mathrm{~cm}$ or $3.72 \%$ [12], achieved similar results.

Regarding the $20 \mathrm{~m}$ sprint (sprint test), the following study showed that the plyometric and strength training improved the performance of the students obtained in this study and specifically with the following results: $-0.32 \mathrm{sec}$. or $9.6 \%$. This finding is the same as the assertion in the study by [13].

The performance of the $5 \times 10 \mathrm{~m}$ high-start jogging test consists of the frequency and speed of the non-stop start, as well as the change of direction and the apparent determinant of explosive muscle strength and flexibility [9].
As we have noted that the plyometric and strength training program enhances explosive muscle strength and flexibility, which is associated with success in the $5 \times 10 \mathrm{~m}$ agility test with a score improvement of $-0.28 \mathrm{sec}$. or $2.13 \%$. The same can be said for the flexibility test, where the improvement is significant, in the flexion of the front trunk by $2.22 \mathrm{~cm}$ or $18.7 \%$, as well as the shoulder rotation from the bottom, front to back $-6.63 \mathrm{~cm}$ or $7.75 \%$. So we conclude that the benefits of strength and power to students have already been proven, after applying or merging some types of strength training into the content of (practical) training sessions [14].

This reality is similar to previous studies which suggest that regular participation in a welldeveloped strength, speed, agility and flexibility training program will undoubtedly result in some level of motor performance improvement [15].

Developing correct and fully supervised application of training programs, from overloads (extra) in skeletal muscles of acting proves avoids injuries during the training process. Therefore contemporary conditioning programs, which include, inter alia, plyometric and force training and applied correctly and rigorously, have proven to be an effective strategy in avoiding or reducing injuries to students [16].

\section{CONCLUSIONS}

1. Discovering, selecting the most efficient methods for enhancing student performance is the first and very important step in the progress of the teachingtraining process.

2. The results of this study are a potential added value in applying the method plyometric program and force during practical lessons in artistic gymnastics, with the intention of maximizing the performance of students in this subject and not only.

3. Our curriculum design combined with the plyometric to force method provides among other things an efficient time in modalities, rational movements in training practice, associated with 
significant improvements in motor performance in these practices and the following.

4. On this basis and the preliminary findings of this study, we conclude that the effects, especially of plyometric and force training, are often synergistic with the impact of increased motor performance on students, rather than the effects of using a single training program of force.

5. The study provided also confirms that it is important to achieve significant statistical progress in motor performance assurance from the training program applied with students in our case.

6. Finally, we think, among other things, that combined plyometric and strength training are a very useful working tool for innovative trainers in the field of strength-training learning, as well as contributing to other time-efficient training.

\section{CONFLICT OF INTEREST}

Authors declare that they have no conflict of interest

\section{ACKNOWLEDGMENTS}

We wish to thank all students, who helped and participated in our study.

\section{REFERENCES}

1. Brooks, T. J. (2003). Women's collegiate gymnastics: A multifactorial approach to training and conditioning. Strength \& Conditioning Journal, 25(2), 23-37.

2. Major, J. J. (1996). Strength training fundamentals in gymnastics conditioning. Technique, 16(8), 115.

3. Malina, R. M., Baxter-Jones, A. D., Armstrong, N., Beunen, G. P., Caine, D., Daly, R. M., \& Russell, K. (2013). Role of intensive training in the growth and maturation of artistic gymnasts. Sports Medicine, 43(9), 783-802.

4. Adams, K., O'Shea, J. P., O'Shea, K. L., \& Climstein, M. (1992). The effect of six weeks of squat, plyometric and squat-plyometric training on power production. Journal of applied sport science research, 6(1), 36-41.

5. Faigenbaum, A. D., McFarland, J. E., Keiper, F. B., Tevlin, W., Ratamess, N. A., Kang, J., \& Hoffman, J. R. (2007). Effects of a short-term plyometric and resistance training program on fitness performance in boys age 12 to 15 years. Journal of sports science \& medicine, 6(4), 519.
6. Fatouros, I. G., Jamurtas, A. Z., Leontsini, D., Taxildaris, K., Aggelousis, N., Kostopoulos, N., \& Buckenmeyer, P. (2000). Evaluation of plyometric exercise training, weight training, and their combination on vertical jumping performance and leg strength. The Journal of Strength \& Conditioning Research, 14(4), 470-476.

7. Linnamo, V., Newton, R. U., Häkkinen, K., Komi, P. V., Davie, A., McGuigan, M., \& TriplettMcBride, T. (2000). Neuromuscular responses to explosive and heavy resistance loading. Journal of Electromyography and Kinesiology, 10(6), 417424.

8. Faigenbaum, A. D., \& Westcott, W. L. (2009). Youth strength trainingprograms for health, fitness, and sport. Human Kinetics.

9. Cometti, G., \& Cometti, D. (2009). "La pliometria" (origini, teorie, allenamento) 2a edizione italiana, Capitolo V: I TEST, Test di Bosco, 4, 60-78.

10. Brown, L. E., \& Faigenbaum, A. D. (2000). Are Plyometrics Safe For Children?. Strength \& Conditioning Journal, 22(3), 45.

11. Croix, G., Chollet, D., \& Thouvarecq, R. (2010). Effect of expertise level on the perceptual characteristics of gymnasts. The Journal of Strength \& Conditioning Research, 24(6), 14581463.

12. Faigenbaum, A. D., Milliken, L., Moulton, L., \& Westcott, W. L. (2005). Early muscular fitness adaptations in children in response to two different resistance training regimens. Pediatric Exercise Science, 17(3), 237-248.

13. Kotzamanidis, C. (2006). Effect of plyometric training on running performance and vertical jumping in prepubertal boys. The Journal of Strength \& Conditioning Research, 20(2), 441-445.

14. Faigenbaum, A. D., Kraemer, W. J., Blimkie, C. J., Jeffreys, I., Micheli, L. J., Nitka, M., \& Rowland, T. W. (2009). Youth resistance training: updated position statement paper from the national strength and conditioning association. The Journal of Strength \& Conditioning Research, 23, S60-S79.

15. Bosco, C. (1997). La forza muscolare: aspetti fisiologici ed applicazioni pratiche. Società stampa sportiva.

16. Atilgan, O. E. (2013). Effects of trampoline training on jump, leg strength, static and dynamic balance of boys. Science of gymnastics journal, 5(2), 15. 